\title{
On the Molecular Modeling Analyses of Novel HIV-1 Protease Inhibitors Based on Modified Chitosan Dimer
}

\author{
Zarrag Al-Fifi, ${ }^{1}$ Noha A. Saleh, ${ }^{2}$ Hanan Elhaes, ${ }^{3}$ and Medhat Ibrahim ${ }^{4}$ \\ ${ }^{1}$ Biology Department, Faculty of Science, Jazan University, Jazan 2097, Saudi Arabia \\ ${ }^{2}$ Biophysics Department, Faculty of Science, Cairo University, Giza 12613, Egypt \\ ${ }^{3}$ Physics Department, Faculty of Women for Arts, Science, and Education, Ain Shams University, Cairo 11757, Egypt \\ ${ }^{4}$ Spectroscopy Department, National Research Center, 33 Buhouth Street, Dokki, Giza 12311, Egypt \\ Correspondence should be addressed to Noha A. Saleh; noha_saleh_kh@yahoo.com
}

Received 30 September 2014; Revised 27 January 2015; Accepted 22 February 2015

Academic Editor: Shigehiko Takegami

Copyright ( 2015 Zarrag Al-Fifi et al. This is an open access article distributed under the Creative Commons Attribution License, which permits unrestricted use, distribution, and reproduction in any medium, provided the original work is properly cited.

\begin{abstract}
The molecular modeling studies include quantitative structure activity relationship, IR spectra, and docking calculations, occurring for novel inhibitors based on chitosan dimer which were tried as HIV protease. The inhibitors were investigated with molecular modeling calculations at different level of theories. Each compound has phenol with hydroxymethylcarbonyl (HMC) group which added to chitosan in positions $2,3,2^{\prime}$, or $3^{\prime}$. The geometry of studied compounds is optimized with semiempirical PM3 method. Quantitative structure activity relationship (QSAR) properties of the suggested compounds are calculated at the same level of theory. Depending on QSAR calculations, the compounds with positions 2 and $2^{\prime}$ are less hydrophilic. The position $2^{\prime}$ compound makes good docking interaction into HIV protease active site. Calculated IR spectra indicate that the interaction through hydrogen bonding through the hydrogen of $\mathrm{OH}$ at positions 3 and $3^{\prime}$ gives rise to two $\mathrm{OH}$ bands one for chitosan and the other for phenol and HMC group. While at position $3^{\prime} \mathrm{CH}$ band starts to appear.
\end{abstract}

\section{Introduction}

Early in 1980s, several cases of death in the US were among patients with Pneumocyctiscarinii pneumonia and Kaposi's sarcoma [1]. All available treatments were tried for the different conditions, but the patients were still passing away. Research activities lead to isolation of new human retrovirus from patients, called the acquired immunodeficiency syndrome (AIDS) $[2,3]$. This retrovirus was known as human immune deficiency virus type 1 (HIV-1). There are two types of HIV: HIV type 1 and HIV type 2. Their genetic sequences are only partially homologous, and they both cause AIDS. HIV-1 is primarily found in the US, Europe, and Asia, and HIV-2 is mostly limited to regions of western Africa [4]. HIV1 carries most of its genetic information in three genes: $\mathrm{gag}$, $\mathrm{pol}$, and env. These genes are expressed as large polyproteins, which are processed into the functional proteins by either the viral protease ( $g a g$ and $p o l$ ) or host cellular enzymes (env) [5-8]. A 12-year longitudinal study was conducted to assess the effects of maternal HIV/AIDS on child/adolescent well-being and behavioral outcomes, extending an earlier published account [9]. A sensitive care is provided for adult HIV-infected women with a history of childhood sexual abuse [10]. The risk of spousal violence in Sub-Sahara is studied [11]. A study is conducted to focus on the effects of bullying on people living with HIV (PLH), a particularly at-risk population [12]. A review is carried out to focus on HIV issues and people with disabilities in more than a decade [13]. In African countries, there are more than 25 million people stricken by HIV/AIDS, so the World Health Organization exerts great effort to improve the antiretroviral therapy and the health care infrastructure [14]. Drugs are divided into four classes with respect to their therapeutic target in the HIV-1 replication cycle. Among these classes are (a) nucleoside reverse transcriptase inhibitors (NRTIs), (b) nonnucleoside reverse transcriptase inhibitors (NNRTIs), (c) protease inhibitors (PIs), and (d) fusion inhibitors [15]. The most common form of treatment up to date is cocktail therapy or highly active antiretroviral therapy (HAART). The HAART regimens may include combinations of one or more 
of NRTI, NNRTI, and PI [16-18]. One of most challenging problems in AIDS therapy is that the HIV virus develops drug-resistant variants rapidly by genetic mutation. The first pharmacological agent that was developed for treatment of HIV infection was the antiretroviral drug zidovudine (ZDV), a nucleoside analog. Some earlier literature refers to ZDV as azidothymidine ( $3^{\prime}$-azido- $3^{\prime}$-deoxythymidine) or AZT [19]. Additional NTRIs were developed, including didanosine (ddI), zalcitabine (ddC), stavudine (d4T), lamivudine (3TC), and abacavir. All of the NRTIs require phosphorylation to an active triphosphate metabolite [17]. The HIV-1 protease can recognize Phe-Pro or Tyr-Pro sequences as the retrovirusspecific cleavage sites, but no mammalian aspartic proteases are known to have such specificity. These features provided a basis for the rational design of selective HIV proteasetargeted drugs for the treatment of AIDS [20]. However, many PIs are lipophilic and poorly soluble. Structural modifications involving the incorporation of polar and ionizable groups have been used to improve the aqueous solubility of these drugs [15]. Another form of antiretroviral therapy is based upon blocking fusion of HIV with the target cell surface to prevent conformational changes to form a stable complex required for membrane fusion to target cells. This drug, enfuvirtide, must be delivered by subcutaneous injection $[15,17]$. The HIV-1 protease was structurally characterized by X-ray crystallography [21]. The flap region regulates substrate entry into the active site by its conformation that is either open, semiopen, or closed [22]. The two subunits are stabilized by intermolecular interactions, and the largest part of the interface is formed by a four-stranded antiparallel $\beta$-sheets consisting of the $\mathrm{N}$ - and $\mathrm{C}$-termini of the protease monomers (residues 1-5 and 95-99) [8]. The active site contains eight C2-symmetric subsites ( $\mathrm{S} 4, \mathrm{~S} 3, \mathrm{~S} 2, \mathrm{~S} 1, \mathrm{S1}^{\prime}, \mathrm{S2}^{\prime}, \mathrm{S}^{\prime}$, and $\mathrm{S4}^{\prime}$ ) [23]. These are the binding sites for the $\mathrm{P} 4, \mathrm{P} 3, \mathrm{P} 2, \mathrm{P} 1, \mathrm{Pl}^{\prime}$, $\mathrm{P}^{\prime}, \mathrm{P}^{\prime}$, and $\mathrm{P} 4^{\prime}$ residues of an octapeptide substrate counted from the bond, which is cleaved during hydrolysis, called the "scissile" bond [21]. Side effects of HIV-1 inhibitors such as drug intolerance and drug toxicity are significant problems for all drugs used to treat HIV and accordingly some kinds of modifications are needed [24-29]. The side effects and the clinical emergence of resistant mutants in HIV-1 mean that new protease inhibitors need to be developed. The cavity of HIV-1 protease active site is about $10 \AA$ in diameter that is close to the diameter of fullerene $\mathrm{C}_{60}$ [30]. Later on, fullerene derivatives were studied as HIV-1 protease inhibitors [31-38] on the basis of molecular modeling using different level of theories. PM3 was conducted to study novel HIV-1 protease inhibitor based on chitosan dimer and applying QSAR and thermodynamic calculations. The inhibition interaction and its mode were confirmed by docking calculation at MM3.

\section{Computational Details}

2.1. Building and Optimized Structures. The novel suggested compounds are built by adding phenol with hydroxymethylcarbonyl (HMC) group to different positions to two units of chitosan as indicated in Figure 1. The SCIGRESS 3.0 molecular modeling software is used to build investigated

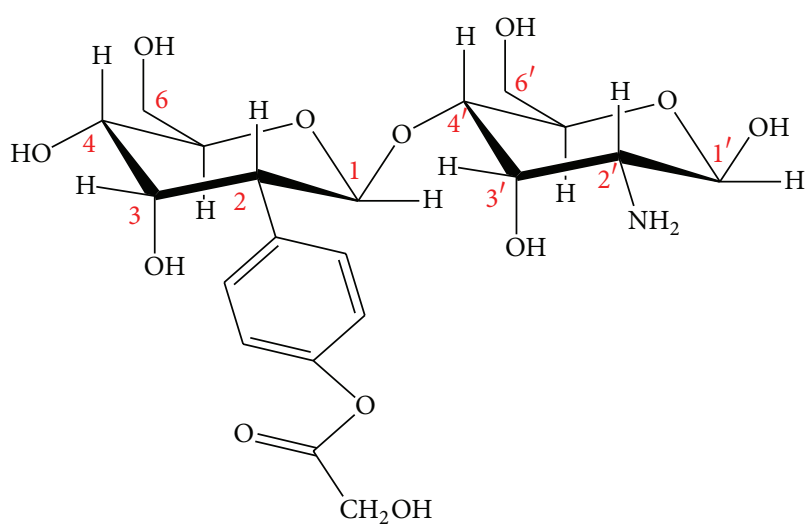

Figure 1: The general structure of suggested compounds. Both phenol and HMC group are added at positions $2,3,2^{\prime}$, or $3^{\prime}$.

compounds [39]. The geometries suggested that compounds are defined by performing geometry optimization calculations using MO-G at PM3 level of theory.

2.2. The Infrared Transitions Spectra. The infrared transitions of the geometry optimized compounds are calculated using MO-G at PM3 level of theory in order to confirm that the investigated compounds are optimized corresponding to energy minimum.

2.3. QSAR Properties. Depending on the optimized compounds, the electronic, QSAR, and thermodynamics properties are calculated at PM3 level. All these calculations are also carried out by SCIGRESS 3.0 molecular modeling software.

2.4. Docking Calculations. The docking molecular simulation is performed at MM3 molecular mechanics method using SCIGRESS 3.0 program. The origin of HIV protease used in this calculation is the Protein Data Bank (PDB code: 4DJO) [40]. After adding the hydrogen atoms, the optimized geometry of HIV protease is calculated using MM3 force field [41]. The conserved catalytic triad residues of HIV protease active sites Asp25, Thr26, and Gly27 (for first monomer of HIV protease) and Asp25', Thr26'. and Gly27' (for second monomer of HIV protease) are selected as group. Performing genetic algorithm, FASTDOCK, and PMF scoring function [42-44] was used to fit the ligand into the selected HIV protease active site residues. The optimization is recalculated for docking systems at MM3 force field.

\section{Results and Discussion}

3.1. The Optimized Structures. As stated earlier, AIDS is considered one of the most widely spread diseases in the world. Until now, the HIV needs new and good inhibitors. The HIV protease enzyme is the most important target to inhibit the AIDS disease.

Figure 1 represents the general structure of the suggested compounds. These compounds are designed to inhibit the HIV protease. The studied compounds are built from mainly 


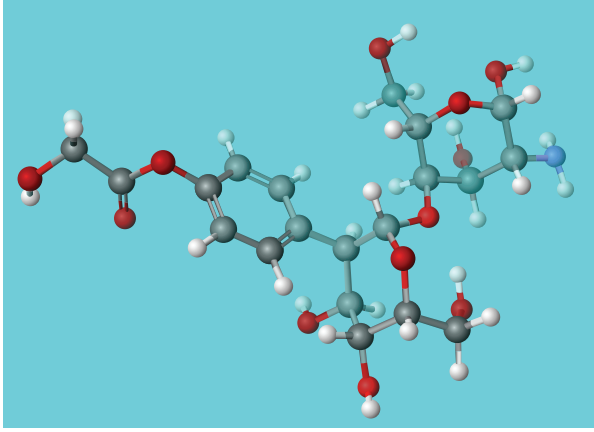

(Position 2)

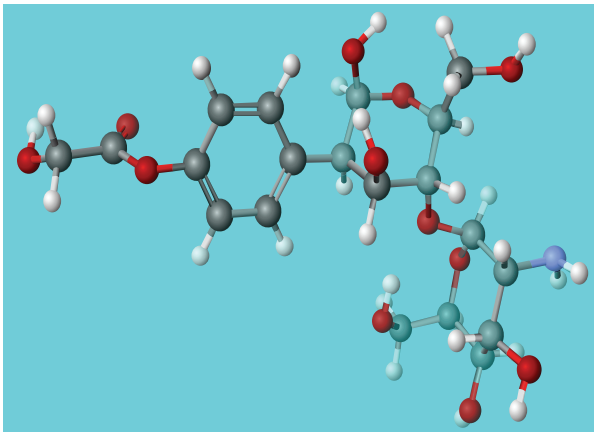

(Position $2^{\prime}$ )

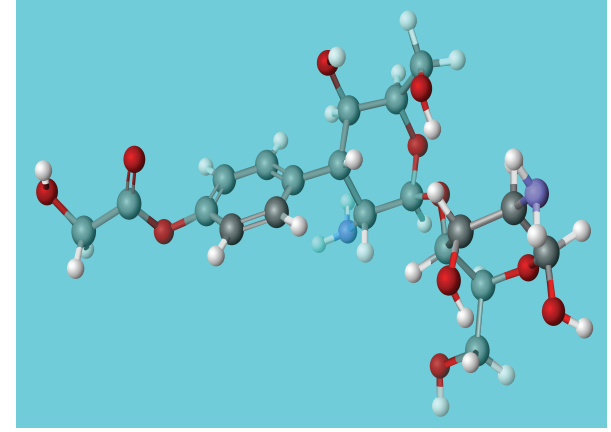

(Position 3)

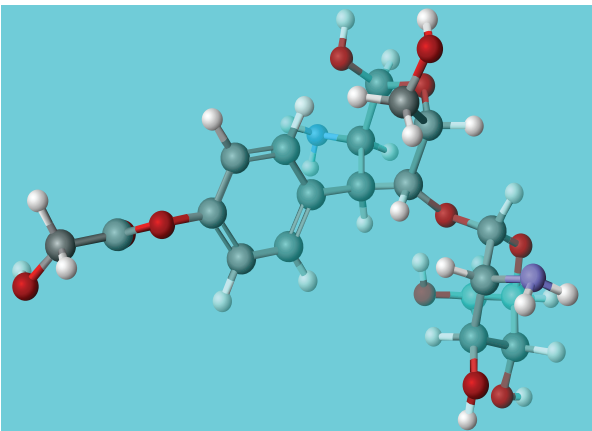

(Position $3^{\prime}$ )

FIgURE 2: The geometry of optimized investigated compounds calculated at PM3 level of theory.

three parts. The first part is two units of chitosan. The twochitosan selection is due to many reasons. The first reason is that the chitosan is considered natural biopolymer. It is one of the most functional polysaccharides owing to its $\mathrm{NH}_{2}$ group. The second reason is that the two units of chitosan are nearly suitable to the diameter of HIV protease active site. The cavity of HIV-1 protease active site is about $10 \AA$ in diameter. From elementary calculations, it is found that the best is two units of chitosan. This is because one unit of chitosan is too small for HIV protease active site and the three units of chitosan were found to be larger than that for HIV protease active site. Finally, the biodegradable nature of chitosan makes it nontoxic and could be safely used in pharmaceutical purposes. In our previous research, a number of modified fullerene based systems were introduced and a new fullerene derivative is suggested as HIV-protease inhibitors [35-37]. The most annoying problem with the synthesis of fullerene-based systems was the coproduction of stool, requiring tedious, expensive, and wasteful procedures for purification [45]. It also can be noticed that the toxicity and insolubility of the fullerene derivatives challenge their use as HIV inhibitors [46, 47], so that in this study the fullerene problems are solved by replacing it with chitosan. The second part of suggested compound is phenol. From our previous study, the compounds have phenyl ring with oxygen atom which are better promising HIV protease inhibitors than those having phenyl ring with sulfur or selenium [35-37]. The third part is the addition of hydroxymethylcarbonyl (HMC) group to phenol. The HMC group showed that it interacted excellently with the catalytic aspartic acid carboxyl groups of

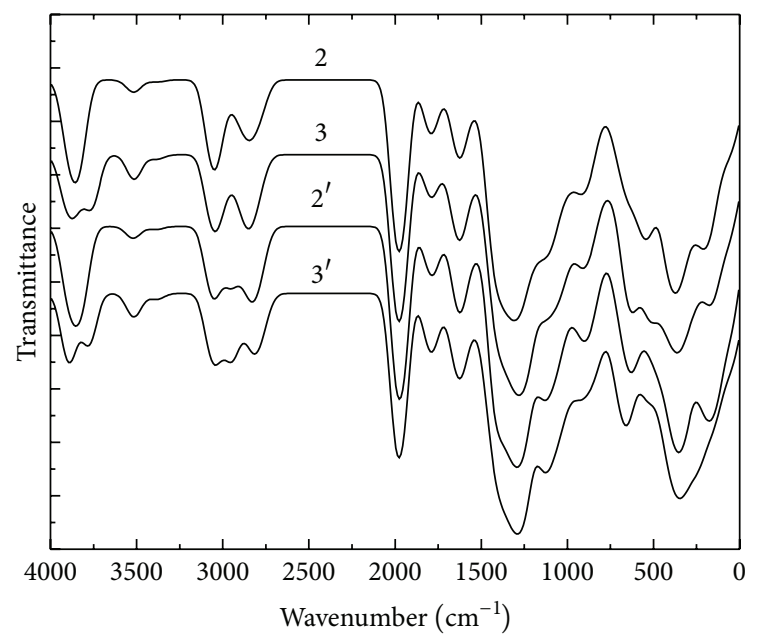

Figure 3: Calculated PM3 spectra for the studied structures.

the HIV protease active site [23]. The second and third parts are added to chitosan at position $2,3,2^{\prime}$, or $3^{\prime}$.

The molecular modeling calculations are performed to the suggested compounds. The semiempirical PM3 optimized geometry of investigated compounds is shown in Figure 2.

3.2. Infrared Spectra. The calculated vibrational spectra could be a good indicator for the given structures. The calculated spectra as indicated in Figure 3 show positive frequencies 
TABLE 1: Some of the calculated QSAR properties of the suggested compounds according to PM3 semiempirical method.

\begin{tabular}{|c|c|c|c|c|c|c|c|c|c|}
\hline $\begin{array}{l}\text { Structure } \\
\text { (position) }\end{array}$ & $\begin{array}{l}\text { Total energy } \\
{[\mathrm{kcal} / \mathrm{mol}]}\end{array}$ & $\begin{array}{c}\text { Heat of } \\
\text { formation } \\
{[\mathrm{kcal} / \mathrm{mol}]}\end{array}$ & $\begin{array}{c}\text { Dipole } \\
\text { moment } \\
\text { [Debye] }\end{array}$ & $\Delta E[\mathrm{eV}]$ & $\begin{array}{c}\text { Ionization } \\
\text { potential } \\
{[\mathrm{eV}]}\end{array}$ & $\log P$ & $\begin{array}{c}\text { Polarizability } \\
\qquad\left[\mathrm{A}^{3}\right]\end{array}$ & $\begin{array}{c}\text { Surface area } \\
{\left[\mathrm{A}^{2}\right]}\end{array}$ & $\begin{array}{l}\text { Volume } \\
{\left[\mathrm{A}^{3}\right]}\end{array}$ \\
\hline 2 & -181131 & -478.205 & 2.327 & 9.527 & -9.834 & -2.142 & 29.883 & 423.370 & 407.740 \\
\hline 3 & -179376 & -435.532 & 4.569 & 9.401 & -9.626 & -2.584 & 30.012 & 427.290 & 413.950 \\
\hline $2^{\prime}$ & -181123 & -474.336 & 2.025 & 9.536 & -9.587 & -2.142 & 29.859 & 423.210 & 405.930 \\
\hline $3^{\prime}$ & -179376 & -431.279 & 0.694 & 9.443 & -9.675 & -2.584 & 30.245 & 427.890 & 413.210 \\
\hline
\end{tabular}

Charge $[\mathrm{e}]=0$ for all the studied compounds.

which indicate that all the studied structures are corresponding to energy minimum; this is one of the tests for the optimization and validity of the calculations.

The spectrum of chitosan was assigned in our previous work $[48,49]$, so that the assignment is not the goal of the present work. The effect of phenol and HMC group upon the chitosan in the positions $2,2^{\prime}, 3$, and $3^{\prime}$ will be assigned.

The calculated spectra indicate the existence of $\mathrm{OH}(3871$ and $3862 \mathrm{~cm}^{-1}$ for positions 2 and $2^{\prime}$, resp., and at 3864 and $3896 \mathrm{~cm}^{-1}$ for positions 3 and $3^{\prime}$, resp.) of chitosan followed by another one for phenol HMC group corresponding to 3 and $3^{\prime}$ positions at 3759 and $3777 \mathrm{~cm}^{-1}$.

This is because phenol and HMC group are added as hydrogen bonding of $\mathrm{NH}_{2}$ at positions 2 and $2^{\prime}$ which in turn broaden the $\mathrm{OH}$. While interaction through hydrogen bonding in the hydrogen of $\mathrm{OH}$ at positions 3 and $3^{\prime}$ gives rise to two $\mathrm{OH}$ bands one for chitosan and the other for phenol and HMC group, the phenol and HMC group at position $3^{\prime}$ gives rise to $\mathrm{CH}$ band, and other vibrational features are the same. Phenyl group exhibits $\mathrm{CH}$ band at $3037 \mathrm{~cm}^{-1}$ which is clearly indicated in case of $3^{\prime}$. There are two respective $\mathrm{OH}$ bands for $2,2^{\prime}$, and 3 positions at 365,355 , and $360 \mathrm{~cm}^{-1}$, respectively. Position $3^{\prime}$ indicates the coupling between two respective $\mathrm{OH}$ to form broad band at $344 \mathrm{~cm}^{-1}$.

3.3. QSAR Descriptors. Table 1 lists some calculated QSAR properties of studied compounds at PM3 level. These QSAR parameters are charge, total energy, heat of formation, total dipole moment, frontier molecular orbital energy gap $\Delta E$ (calculated as LUMO-HOMO energy difference), ionization potential, $\log p$, polarizability, surface area, and volume. All suggested compounds are in ground state not in exited ones. Therefore, the charge of compounds equals zero. The total energy of compounds with positions 2 and $2^{\prime}$ is nearly the same and is equal to $-181131 \mathrm{Kcal} / \mathrm{mol}$ and $-181123 \mathrm{Kcal} / \mathrm{mol}$ for position 2 and $2^{\prime}$, respectively. While the total energy of compounds with positions 3 and $3^{\prime}$ is typically the same, the value of this total energy is $-179376 \mathrm{Kcal} / \mathrm{mol}$. The compounds with positions 2 and $2^{\prime}$ are more stable than compounds with positions 3 and $3^{\prime}$. The third QSAR parameter listed in Table 1 is the heat of formation. The heat of formation is known as the change in enthalpy accompanying the formation of one mole of a compound from its elements in their natural and stable states, under standard conditions of one atmosphere at a given temperature [50]. The final heat of formation of studied compounds is varying from
$-478.21 \mathrm{Kcal} / \mathrm{mol}$ to $-431.28 \mathrm{Kcal} / \mathrm{mol}$. The compound with position 2 has the lowest heat of formation and needs small change in enthalpy to form one mole of this compound, while the compound with position $3^{\prime}$ has the highest heat of formation and needs large change in enthalpy to form one mole of this compound.

Table 1 represents three parameters as indicators of the reactivity of suggested compounds. These parameters are $\Delta E$, ionization potential, and total dipole moment. $\Delta E$ is the frontier molecular orbital energy gap. The smaller the frontier molecular orbital energy gap $(\Delta E)$ of a molecule is, the more reactive the molecule with its surrounding medium is. According to Table 1, $\Delta E$ of the compounds with positions 3 and $3^{\prime}$ has lower $\Delta E$ value than that of compounds with 2 and $2^{\prime}$. This indicates that the compounds with positions 3 and $3^{\prime}$ are more reactive with the surrounding system and may be reacting well with the HIV protease active site. The ionization potential (i.e., the electron detachment energy) is the energy required to remove an electron from the molecule to a practically infinite distance. The lowest ionization potential value is $-9.83 \mathrm{eV}$ for the compound with position 2 compared to compounds with position 3 and $3^{\prime}$. The highest ionization potential value is $-9.59 \mathrm{eV}$ for the compound with position $2^{\prime}$. The compounds with position 2 can easily remove an electron, while the compound with position $2^{\prime}$ can hardly remove an electron and interact with other compounds. On the contrary of $\Delta E$ and ionization potential values, there is large difference in total dipole moment values for the investigated compounds. The values of dipole moment are varying from 0.69 Debye to 4.57 Debye. It is stated that if the total dipole moment of certain structure increases, then its molecular reactivity increases as well, and accordingly the given structure becomes more interacting with other systems strongly in solution [51]. The compound with position 3 has the highest value of total dipole moment and may have more reactivity and attractiveness than the surrounding structures in biological system. The compound with position $3^{\prime}$ has the lowest total dipole moment value and is considered less reactive than the surrounding system.

The logarithm of the partition coefficient $\log p$ gives information about the compound whether it is hydrophilic or hydrophobic molecule. If the $\log p$ value is positive, the molecule will be hydrophobic and more soluble in the organic solvents. If the $\log p$ value is negative, the molecule will be hydrophilic and more soluble in aqueous buffer. From Table 1, the compounds with positions 3 and $3^{\prime}$ are more hydrophilic 
TABLE 2: Calculated heat of formation, heat capacity, enthalpy, entropy, and free energy for the different positions of the structure calculated at PM3 semiempirical quantum mechanical method at 298 Kelvin.

\begin{tabular}{lccccc}
\hline $\begin{array}{l}\text { Structure } \\
\text { (position) }\end{array}$ & $\begin{array}{c}\text { Heat of formation } \\
(\mathrm{Kcal} / \mathrm{mol})\end{array}$ & $\begin{array}{c}\text { Heat capacity } \\
(\mathrm{cal} / \mathrm{mol} / \text { Kelvin) }\end{array}$ & Enthalpy $(\mathrm{Kcal} / \mathrm{mol})$ & $\begin{array}{c}\text { Entropy } \\
(\mathrm{cal} / \mathrm{mol} / \mathrm{Kelvin})\end{array}$ & $\begin{array}{c}\text { Free energy } \\
(\mathrm{Kcal} / \mathrm{mol})\end{array}$ \\
\hline 2 & -478.205 & 127.305 & 21.187 & 211.767 & -303.852 \\
3 & -435.505 & 128.232 & 21.361 & 214.734 & -257.868 \\
$2^{\prime}$ & -474.336 & 128.479 & 21.573 & 214.923 & -300.924 \\
$3^{\prime}$ & -431.279 & 128.250 & 21.197 & 209.766 & -252.162 \\
\hline
\end{tabular}

TABLE 3: Calculated heat of formation, heat capacity, enthalpy, entropy, and free energy as a function of temperate for the studied structure in position 2 calculated at PM3 semiempirical quantum mechanical method.

\begin{tabular}{lccccc}
\hline Temperature & $\begin{array}{c}\text { Heat of formation } \\
(\mathrm{Kcal} / \mathrm{mol})\end{array}$ & $\begin{array}{c}\text { Heat capacity } \\
(\mathrm{cal} / \mathrm{mol} / \mathrm{Kel} \text { in })\end{array}$ & Enthalpy (Kcal/mol) & $\begin{array}{c}\text { Entropy } \\
(\mathrm{cal} / \mathrm{mol} / \text { Kelvin })\end{array}$ & $\begin{array}{c}\text { Free energy } \\
(\mathrm{Kcal} / \mathrm{mol})\end{array}$ \\
\hline 200 & -488.912 & 91.383 & 10481 & 168.676 & -363.278 \\
250 & -483.890 & 109.564 & 15503 & 191.013 & -332.432 \\
300 & -477.950 & 128.044 & 21443 & 212.621 & -302.683 \\
350 & -471.090 & 146.259 & 28303 & 233.735 & -274.002 \\
400 & -463.340 & 163.551 & 36053 & 254.407 & -246.365 \\
450 & -454.757 & 179.507 & 44636 & 274.606 & -219.750 \\
500 & -445.414 & 193.979 & 53979 & 294.281 & -194.133 \\
\hline
\end{tabular}

and soluble in biological system than the compounds with positions 2 and $2^{\prime}$. Surface area and volume of investigated compounds are shown in Table 1 . The surface area of the compounds with positions 2 and $2^{\prime}$ has nearly the same values of surface area and volume. In addition, the surface area and volume of compounds with positions 3 and $3^{\prime}$ have nearly the same values. As a result of the presence of $\mathrm{NH}_{2}$ group in compounds with positions 3 and $3^{\prime}$, the surface area and volume of these compounds are larger than the surface area and volume of the compounds with positions 2 and $2^{\prime}$. The polarizability values are volume dependent. Therefore, the polarizability of the compounds with positions 3 and $3^{\prime}$ is more than those with positions 2 and $2^{\prime}$.

3.4. Thermodynamics Properties. Table 2 presents the calculated heat of formation, heat capacity, enthalpy, entropy, and free energy of the different positions of the studied structures which were calculated at PM3 semiempirical quantum mechanical method at 298 Kelvin.

Thermal parameters are considered very important parameters to describe the physical behavior of chemical and/or biological system interacting with its surroundings in the presence of heat. Thermal parameters are indicators for a given structure for its ability, behavior when it is subjected to heat, or even exchange heat from its surroundings. For example, the heat of formation is the heat evolved or absorbed when one mole of a compound is formed. Heat capacity is representing the amount of energy required to produce a unit temperature rise. Enthalpy is a measure of the total energy while entropy is a measure of the number of specific ways in which a system may be arranged. Free energy is the energy in a physical system that can be converted to do work [52]. From the table, one can see that the calculated heat of formations of position 2 and position $2^{\prime}$ is -478.205 and $-474.336 \mathrm{Kcal} / \mathrm{mol}$, while position 3 and position $3^{\prime}$ have a little bit higher heat of formations which is -435.505 and $-431.279 \mathrm{Kcal} / \mathrm{mol}$, respectively. The same behavior is observed for the free energy where position 2 and position $2^{\prime}$ have free energy $(-303.852$ and $-300.924 \mathrm{Kcal} / \mathrm{mol}$, resp.) a little lower than position 3 and position $3^{\prime}(-257.868$ and $-252.162 \mathrm{Kcal} / \mathrm{mol}$, resp.). Heat capacity, enthalpy, and entropy show nearly no change in the different four positions. This means that the structure is thermally stable at room temperature.

Table 3 presents the calculated heat of formation, heat capacity, enthalpy, entropy, and free energy as a function of temperature in the range 200 to 500 Kelvin for the studied structure in position 2 calculated at PM3 semiempirical quantum mechanical method. From the table, all the thermal parameters increase with increasing temperature.

3.5. Docking Simulation. The docking calculation of suggested compounds into the HIV protease active site is performed at MM3 force field. Figure 4 represents the mode of interaction between studied compounds and HIV protease active site. From Figure 4, the left and right figures of docking interaction with position 2 compound illustrate the mode of interaction with chitosan dimer and HMC group, respectively. The chitosan dimer of the compound with position 2 forms seven hydrogen bonds with Thr80, Ala28', Gly27', Asp25', and Asp25, while the HMC group of the compound with position 2 forms only one hydrogen bond with Gly 27. The interaction of position 3 compound is through the chitosan dimer only by forming three hydrogen bonds with Asp25. About position $2^{\prime}$ compound in Figure 4, the left and right figures show the mode of interaction with chitosan dimer and HMC group, respectively. The chitosan dimer of 


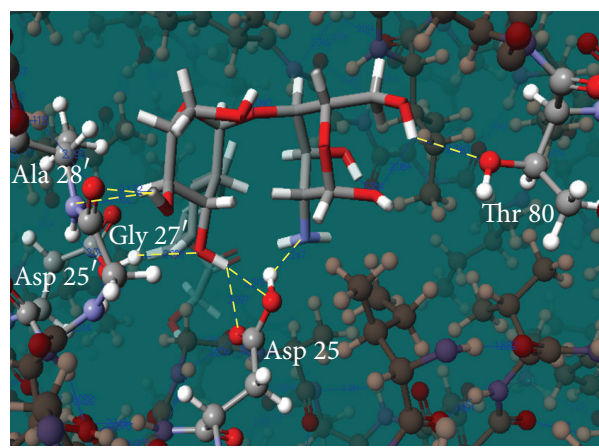

(Position 2)

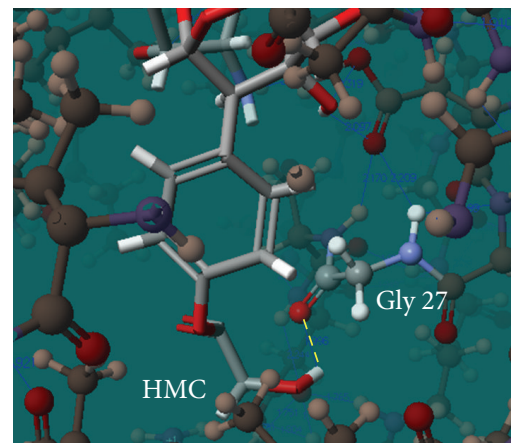

(Position 2)

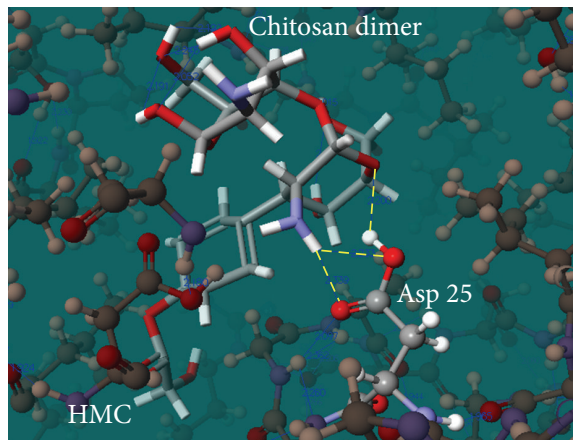

(Position 3)

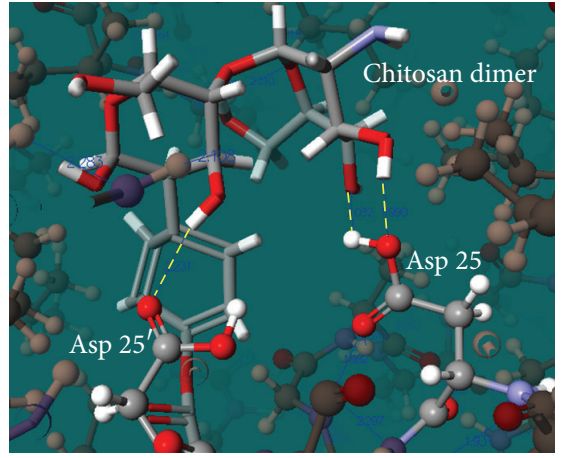

$\left(\right.$ Position $2^{\prime}$ )

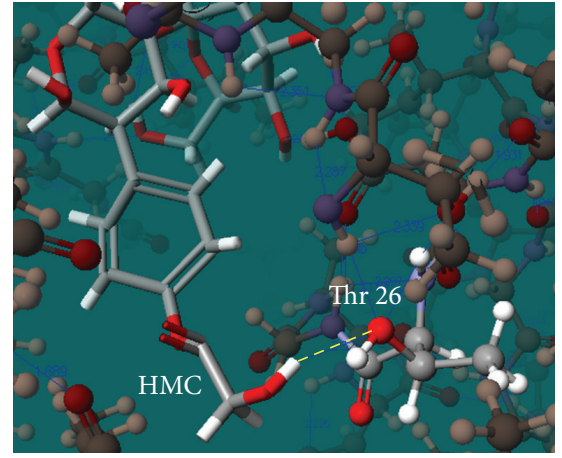

(Position 2')

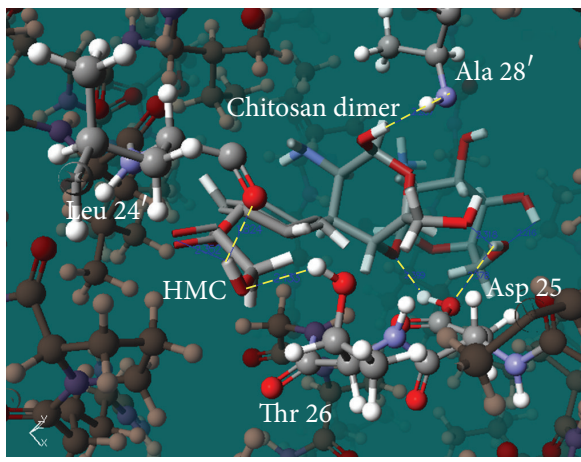

(Position 3')

FIGURE 4: The docking systems and mode of interaction between ligands and HIV protease. The cylinder molecule is considered the studied compound and the ball and rod molecule is considered the amino acids of protein. The dashed lines represented the hydrogen bond interaction. The symbol $\left({ }^{\prime}\right)$ represents the residues in second monomer of HIV protease. 
TABLE 4: The total energy, docking score, and the number of hydrogen bonds between the ligand and protein of docking (interaction) systems via MM3 force field method.

\begin{tabular}{lccc}
\hline $\begin{array}{l}\text { Structure } \\
\text { (position) }\end{array}$ & $\begin{array}{c}\text { Total energy } \\
(\text { Kcal/mol) }\end{array}$ & $\begin{array}{c}\text { Docking } \\
\text { score }\end{array}$ & $\begin{array}{c}\text { Number of } \mathrm{H} \\
\text { bonds }\end{array}$ \\
\hline 2 & 60.06 & 2786.48 & 8 \\
3 & -45.61 & 2708.13 & 3 \\
$2^{\prime}$ & -123.57 & 1638.50 & 4 \\
$3^{\prime}$ & 13.73 & 9433.26 & 5 \\
\hline
\end{tabular}

position $2^{\prime}$ compound interacts with Asp25 and Asp $25^{\prime}$ to form three hydrogen bonds. The HMC group of position $2^{\prime}$ compound interacts with Thr26 by forming one hydrogen bond. The docking of position $3^{\prime}$ compound into HIV protease active site produces two sites of interactions. The first is by forming three hydrogen bonds between chitosan dimer and Ala28' and Asp25. The second is by forming two hydrogen bonds between HMC group and Leu24' and Thr26.

Table 4 shows the total energy and docking score of docking systems molecular mechanics MM3 force field. Also this table represents the number of hydrogen bonds formed between the compounds and the HIV protease active site. The total energy of docking system with position $2^{\prime}$ compound is the lowest and is equal to $-123.57 \mathrm{Kcal} / \mathrm{mol}$. But the highest total energy value of docking system is $60.06 \mathrm{Kcal} / \mathrm{mol}$ for position 2 compound. From docking score results in Table 4, there is similar relation between the total energy and docking score. The lowest total energy of docking interaction system is for compound with positions $2^{\prime}$, then 3 , then $3^{\prime}$, and then 2 which has highest total energy value. Also the lowest docking score value is for compound with position $2^{\prime}$, then 3 , then $3^{\prime}$, and then 2 which has highest value. As shown in Figure 4 and Table 4 , the compounds with positions $2,3,2^{\prime}$, and $3^{\prime}$ form 8 , 4,3 , and 5 hydrogen bonds with HIV protease, respectively.

\section{Conclusion}

Biodegradable polysaccharides such as chitosan dimer could be modified to carry out phenol and HMC group in order to own hydrogen bonding with suitable geometry to act as HIV protease inhibitor. All the investigated compounds may be used more safety as HIV protease inhibitor than fullerene derivatives. From the point of view of total energy and heat of formation, the compounds with positions 2 and $2^{\prime}$ are more stable. However, from the standpoint of reactivity parameters ( $\Delta E$, ionization potential, and total dipole moment) and solubility $(\log p)$, the compounds with positions 3 and $3^{\prime}$ are more soluble and reactive. In addition to the compounds with positions 2 and $2^{\prime}$ which make masking to the $\mathrm{NH}_{2}$ group which gives the chitosan its properties and functionality, the studied thermal parameters indicate that the proposed structures are thermally stable in terms of the calculated thermal parameters.

According to the docking simulation, there is competition between the chitosan dimer and HMC group to form the hydrogen bonds with HIV protease but the winner is the chitosan dimer. Most of forming hydrogen bonds in docking interaction are through the chitosan dimer. Due to the HIV protease, active site residues are hydrophobic except Asp 25 and Asp 25', and the compounds with high polarity will not form good interaction with HIV protease, so that the docking simulation with position $2^{\prime}$ compound which is less hydrophilic makes most stable interaction and acts as promising HIV protease inhibitor.

\section{Conflict of Interests}

The authors declare that there is no conflict of interests regarding the publication of this paper.

\section{References}

[1] M. S. Gottlieb, R. Schroff, H. M. Schanker et al., "Pneumocystis carinii pneumonia and mucosal candidiasis in previously healthy homosexual men-evidence of a new acquired cellular immunodeficiency," The New England Journal of Medicine, vol. 305, no. 24, pp. 1425-1431, 1981.

[2] R. C. Gallo, P. S. Sarin, E. P. Gelmann et al., "Isolation of human T-cell leukemia virus in acquired immune deficiency syndrome (AIDS)," Science, vol. 220, no. 4599, pp. 865-867, 1983.

[3] F. Barre Sinoussi, J. C. Chermann, F. Rey et al., "Isolation of a T-lymphotropic retrovirus from a patient at risk for acquired immune deficiency syndrome (AIDS)," Science, vol. 220, no. 4599, pp. 868-871, 1983.

[4] M. Guyader, M. Emerman, P. Sonigo, F. Clavel, L. Montagnier, and M. Alizon, "Genome organization and transactivation of the human immunodeficiency virus type 2," Nature, vol. 326, no. 6114, pp. 662-669, 1987.

[5] B. G. Turner and M. F. Summers, "Structural biology of HIV," Journal of Molecular Biology, vol. 285, no. 1, pp. 1-32, 1999.

[6] E. O. Freed, "HIV-1 Gag proteins: diverse functions in the virus life cycle," Virology, vol. 251, no. 1, pp. 1-15, 1998.

[7] E. O. Freed, "HIV-1 replication," Somatic Cell and Molecular Genetics, vol. 26, no. 1-6, pp. 13-33, 2001.

[8] N. Sluis-Cremer and G. Tachedjian, "Modulation of the oligomeric structures of HIV-1 retroviral enzymes by synthetic peptides and small molecules," European Journal of Biochemistry, vol. 269, no. 21, pp. 5103-5111, 2002.

[9] D. A. Murphy, W. D. Marelich, and D. M. Herbeck, "Impact of maternal HIV health: A 12-year study of children in the parents and children coping together project," Journal of Adolescent Health, vol. 51, no. 4, pp. 313-318, 2012.

[10] E. Aaron, S. Criniti, A. Bonacquisti, and P. A. Geller, "Providing sensitive care for adult HIV-infected women with a history of childhood sexual abuse," The Journal of the Association of Nurses in AIDS Care, vol. 24, no. 4, pp. 355-367, 2013.

[11] Y.-M. Chin, "Does HIV increase the risk of spousal violence in sub-Saharan Africa?” Journal of Health Economics, vol. 32, no. 5, pp. 997-1006, 2013.

[12] C. Kamen, J. Bergstrom, C. Vorasarun et al., "The impact of childhood bullying among HIV-positive men: psychosocial correlates and risk factors," Child Abuse and Neglect, vol. 37, no. 4, pp. 273-281, 2013.

[13] N. E. Groce, P. Rohleder, A. H. Eide, M. MacLachlan, S. Mall, and L. Swartz, "HIV issues and people with disabilities: a review and agenda for research," Social Science \& Medicine, vol. 77, pp. 31-40, 2013. 
[14] A. Bhargava, "The AIDS epidemic and health care infrastructure inadequacies in Africa: a socioeconomic perspective," Journal of Acquired Immune Deficiency Syndromes, vol. 40, pp. 241-242, 2005.

[15] E. Jenny, Design and synthesis of novel HIV-1 protease inhibitors comprising a tertiary alcohol in the transition-state mimic [Ph.D. dissertation], University of Uppsala, Uppsala, Sweden, 2006.

[16] T. Bini, L. Testa, E. Chiesa et al., "Outcome of a second-line protease inhibitor-containing regimen in patients failing or intolerant of a first highly active antiretroviral therapy," Journal of Acquired Immune Deficiency Syndromes, vol. 24, no. 2, pp.115$122,2000$.

[17] K. C. Edward, Pathology of AIDS, Version 25, Utah State University Library, Logan, Utah, USA, 2014, http://library.med.utah .edu/WebPath/AIDS2014.PDF.

[18] R. Murri, A. Ammassari, K. Gallicano et al., "Patient-reported nonadherence to HAART is related to protease inhibitor levels," Journal of Acquired Immune Deficiency Syndromes, vol. 24, no. 2, pp. 123-128, 2000.

[19] M. S. Hirsch and R. T. D'Aquila, "Therapy for human immunodeficiency virus infection," The New England Journal of Medicine, vol. 328, no. 23, pp. 1686-1695, 1993.

[20] Y. Kiso, H. Matsumoto, S. Yamaguchi, and T. Kimura, "Design of small peptidomimetic HIV-1 protease inhibitors and prodrug forms," Letters in Peptide Science, vol. 6, no. 5-6, pp. 275-281, 1999.

[21] A. Wlodawer and J. W. Erickson, "Structure-based inhibitors of HIV-1 protease," Annual Review of Biochemistry, vol. 62, pp. 543-585, 1993.

[22] V. Hornak and C. Simmerling, "Targeting structural flexibility in HIV-1 protease inhibitor binding," Drug Discovery Today, vol. 12, no. 3-4, pp. 132-138, 2007.

[23] H. O. Andersson, K. Fridborg, S. Löwgren et al., "Optimization of P1-P3 groups in symmetric and asymmetric HIV-1 protease inhibitors," European Journal of Biochemistry, vol. 270, no. 8, pp. 1746-1758, 2003.

[24] A. Arenas-Pinto, A. D. Grant, S. Edwards, and I. V. D. Weller, "Lactic acidosis in HIV infected patients: a systematic review of published cases," Sexually Transmitted Infections, vol. 79, no. 4, pp. 340-344, 2003.

[25] A. H. Essa, M. Ibrahim, A. J. Hameed, and N. A. AlMasoudi, "Theoretical investigation of $3^{\prime}$-subtituted-2'- $3^{\prime}$ dideoxythymidines related to AZT. QSAR infrared and substituent electronic effect studies," ARKIVOC, vol. 2008, no. 13, pp. 255-265, 2008.

[26] A. P. Lea and D. Faulds, "Stavudine: a review of its pharmacodynamic and pharmacokinetic properties and clinical potential in HIV infection," Drugs, vol. 51, no. 5, pp. 846-864, 1996.

[27] K. Brinkman, H. J. M. ter-Hofstede, D. M. Burger, J. A. M. Smeitink, and P. P. Koopmans, "Adverse effects of reverse transcriptase inhibitors: mitochondrial toxicity as common pathway," AIDS, vol. 12, no. 14, pp. 1735-1744, 1998.

[28] M. S. Sulkowski, D. L. Thomas, R. E. Chaisson, and R. D. Moore, "Hepatotoxicity associated with antiretroviral therapy in adults infected with human immunodeficiency virus and the role of hepatitis C or B virus infection," The Journal of the American Medical Association, vol. 283, no. 1, pp. 74-80, 2000.

[29] C. Flexner, "HIV-protease inhibitors," The New England Journal of Medicine, vol. 338, no. 18, pp. 1281-1292, 1998.

[30] S. H. Friedman, D. L. Decamp, R. P. Sijbesma, G. Srdanov, F. Wudl, and G. L. Kenyon, "Inhibition of the HIV-1 protease by fullerene derivatives: model building studies and experimental verification," Journal of the American Chemical Society, vol. 115, no. 15, pp. 6506-6509, 1993.

[31] D. I. Schuster, S. R. Wilson, and R. F. Schinazi, "Anti-human immunodeficiency virus activity and cytotoxicity of derivatized buckminsterfullerenes," Bioorganic \& Medicinal Chemistry Letters, vol. 6, no. 11, pp. 1253-1256, 1996.

[32] G. L. Marcorin, T. da Ros, S. Castellano et al., "Design and synthesis of novel [60]fullerene derivatives as potential HIV aspartic protease inhibitors," Organic Letters, vol. 2, no. 25, pp. 3955-3958, 2000.

[33] S. Bosi, T. D. Ros, G. Spalluto, J. Balzarini, and M. Prato, "Synthesis and anti-HIV properties of new water-soluble bisfunctionalized[60]fullerene derivatives," Bioorganic \& Medicinal Chemistry Letters, vol. 13, no. 24, pp. 4437-4440, 2003.

[34] S. Bosi, T. da Ros, G. Spalluto, and M. Prato, "Fullerene derivatives: an attractive tool for biological applications," European Journal of Medicinal Chemistry, vol. 38, no. 11-12, pp. 913-923, 2003.

[35] V. Hornak, A. Okur, R. C. Rizzo, and C. Simmerling, "HIV1 protease flaps spontaneously open and reclose in molecular dynamics simulations," Proceedings of the National Academy of Sciences of the United States of America, vol. 103, no. 4, pp. 915920, 2006.

[36] M. Ibrahim, N. A. Saleh, W. M. Elshemey, and A. A. Elsayed, "Computational notes on fullerene based system as HIV-1 protease inhibitors," Journal of Computational and Theoretical Nanoscience, vol. 7, no. 1, pp. 224-227, 2010.

[37] M. Ibrahim, N. A. Saleh, A. J. Hameed, W. M. Elshemey, and A. A. Elsayed, "Structural and electronic properties of new fullerene derivatives and their possible application as HIV-1 protease inhibitors," Spectrochimica Acta, Part A: Molecular and Biomolecular Spectroscopy, vol. 75, no. 2, pp. 702-709, 2010.

[38] M. Ibrahim, N. A. Saleh, W. M. Elshemey, and A. A. Elsayed, "Fullerene derivative as anti-HIV protease inhibitor: molecular modeling and QSAR approaches," Mini-Reviews in Medicinal Chemistry, vol. 12, no. 6, pp. 447-451, 2012.

[39] J. J. P. Stewart, SCIGRESS, Version 2.9.0, Fujitsu Limited, Sunnyvale, Calif, USA, 2009.

[40] M. K. Parai, D. J. Huggins, H. Cao et al., "Design, synthesis, and biological and structural evaluations of novel HIV-1 protease inhibitors to combat drug resistance," Journal of Medicinal Chemistry, vol. 55, no. 14, pp. 6328-6341, 2012.

[41] J.-H. Lii and N. L. Allinger, "Molecular Mechanics. The MM3 force field for hydrocarbons. 3. The van der Waals' potentials and crystal data for aliphatic and aromatic hydrocarbons," Journal of the American Chemical Society, vol. 111, no. 23, pp. 8576-8582, 1989.

[42] I. Muegge, "A knowledge-based scoring function for proteinligand interactions: probing the reference state," Perspectives in Drug Discovery and Design, vol. 20, no. 1, pp. 99-114, 2000.

[43] I. Muegge, "PMF scoring revisited," Journal of Medicinal Chemistry, vol. 49, no. 20, pp. 5895-5902, 2006.

[44] H. I. A. Mostafa, N. S. El-bialy, A. A. Ezat, N. A. Saleh, and M. A. Ibrahim, "QSAR analysis and molecular docking simulation of suggested peptidomimetic NS3 protease inhibitors," Current Computer-Aided Drug Design, vol. 10, no. 1, pp. 28-40, 2014.

[45] R. P. Rodgers, P. T. A. Reilly, W. B. Whitten, and J. M. Ramsey, "Soot-free synthesis of C $_{60}$ " Carbon, vol. 41, no. 8, pp. 1469-1475, 2003.

[46] R. Taylor and D. R. M. Walton, "The chemistry of fullerenes," Nature, vol. 363, no. 6431, pp. 685-693, 1993. 
[47] C. Y. Shu, L. H. Gan, C. R. Wang, X. L. Pei, and H. B. Han, "Synthesis and characterization of a new water-soluble endohedral metallofullerene for MRI contrast agents," Carbon, vol. 44, no. 3, pp. 496-500, 2006.

[48] E.-S. M. El-Sayed, A. Omar, M. Ibrahim, and W. I. AbdelFattah, "On the structural analysis and electronic properties of chitosan/hydroxyapatite interaction," Journal of Computational and Theoretical Nanoscience, vol. 6, no. 7, pp. 1663-1669, 2009.

[49] M. Ibrahim, O. Osman, and A. A. Mahmoud, "Spectroscopic analyses of cellulose and chitosan: FTIR and modeling approach," Journal of Computational and Theoretical Nanoscience, vol. 8, no. 1, pp. 117-123, 2011.

[50] M. L. Lakhanpal, Fundamentals of Chemical Thermodynamics, Tata McGraw-Hill Publishing Company Limited, 1983.

[51] M. Ibrahim and H. El-Haes, "Computational spectroscopic study of copper, cadmium, lead and zinc interactions in the environment," International Journal of Environment and Pollution, vol. 23, no. 4, pp. 417-424, 2005.

[52] B. H. Lavenda, A New Perspective on Thermodynamics, Springer, New York, NY, USA, 2009. 

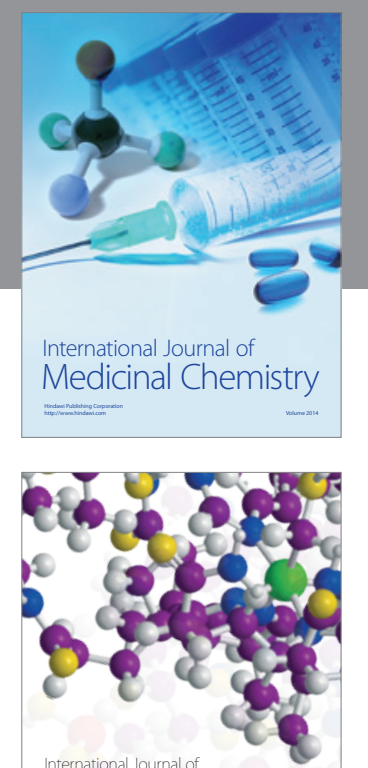

\section{Carbohydrate} Chemistry

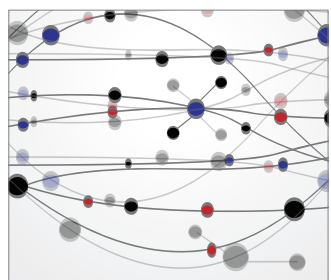

The Scientific World Journal
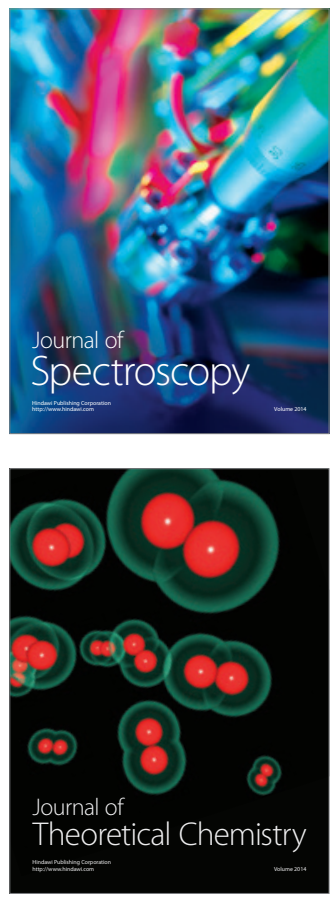
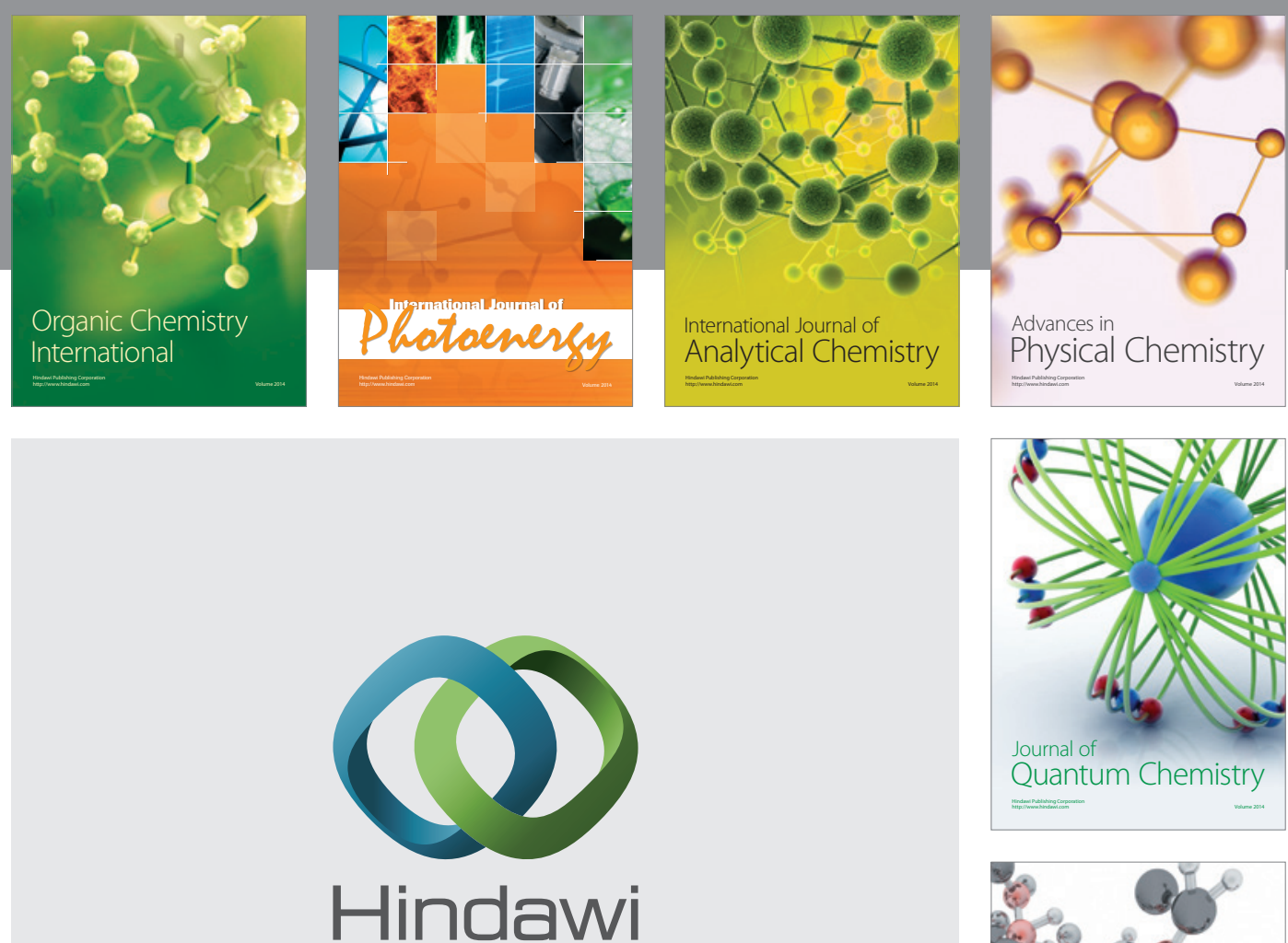

Submit your manuscripts at

http://www.hindawi.com

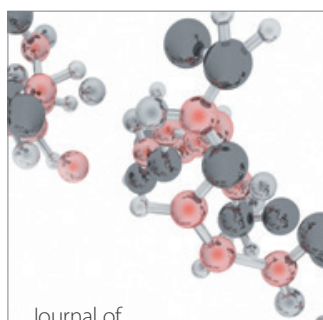

Analytical Methods

in Chemistry

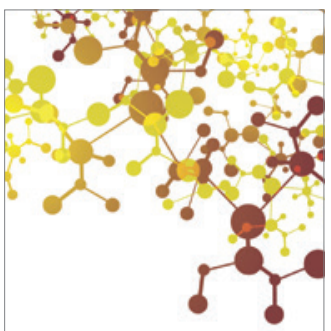

Journal of

Applied Chemistry

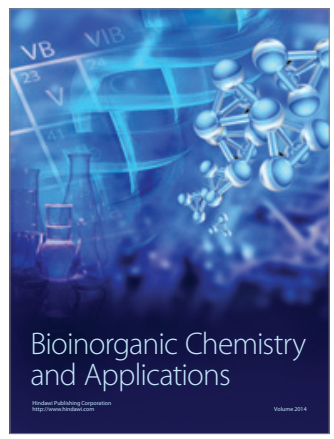

Inorganic Chemistry
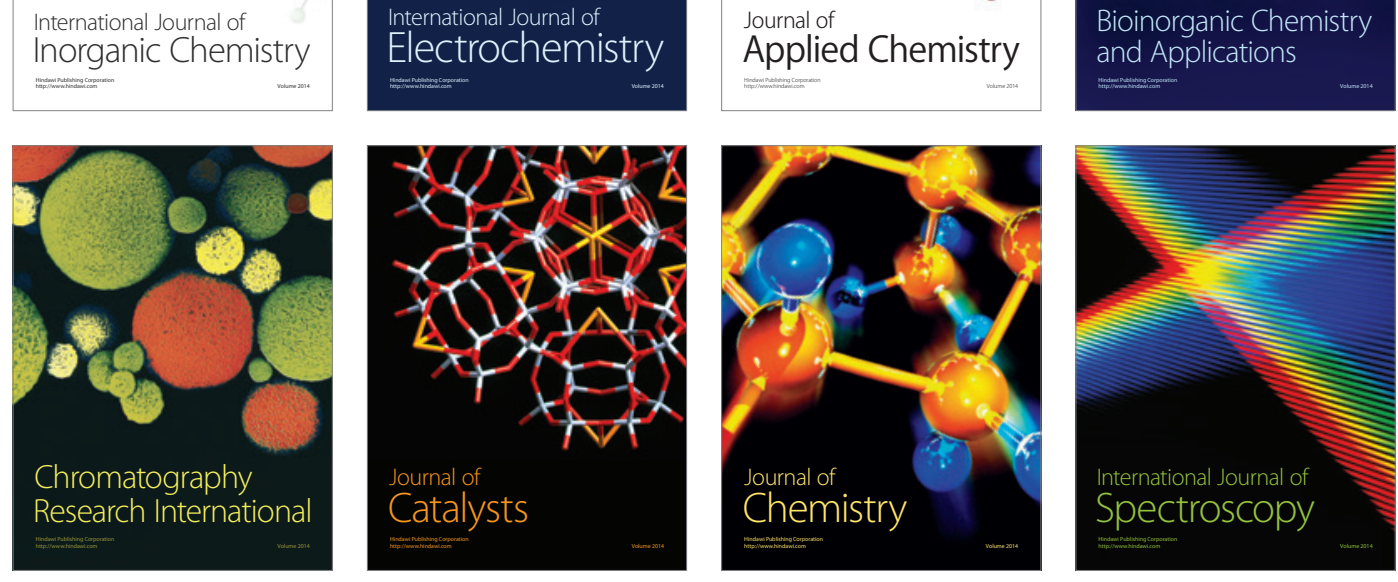